\title{
MAPPING THE ENVIRONMENTAL SENSITIVITY TO OIL SPILL AND LAND USE/LAND COVER USING SPECTRALLY TRANSFORMED LANDSAT 7 ETM DATA
}

\author{
CARVALHO, M. ${ }^{1}$ \& GHERARDI, D.F.M. ${ }^{2}$ \\ 1Oceanography Institute, São Paulo University, Oceanográfico square, 191, CEP 05508-120, São \\ Paulo, Brazil, melissa@io.usp.br
}
${ }^{2}$ Remote Sensing Division, National Institute for Space Research-INPE, Av. dos Astronautas, 1758, CEP 12227-010, São José dos Campos, São Paulo, Brazil, douglas@dsr.inpe.br

\begin{abstract}
Carvalho, M. \& Gherardi, D.F.M. 2008. Mapping the environmental sensitivity to oil spill and land use/land cover using spectrally transformed Landsat 7 ETM data. Braz. J. Aquat. Sci. Technol. 12(2):1-9. ISSN 18087035. Accidents involving oil spill in the marine environment cause a number of impacts on biological communities and impose severe damages on human-use resources. Environmental sensitivity index (ESI) maps are an integral component of oil spill contingency planning and emergency response. ESI maps can also be used for environment management planning by adding land use/land cover (LULC) information on shoreline classification, biological and human-use resources. We have assessed the adequacy of restored ETM+/Landsat 7 images to generate ESI and LULC maps for a stretch of coastline between the cities of Areia Branca (RN) and Fortim (CE) in the Potiguar sedimentary basin, Northeast Brazil. This has been done by comparing results from segmentation by region growth and unsupervised classification of images generated by standard and selective principal components, IHS transform, soil adjusted vegetation index, and linear spectral mixture model. The assignment of image classes to map themes was aided by visual interpretation of digitally processed images and ground truth. Results clearly indicate that image restoration followed by fusion of multispectral and panchromatic ETM images via IHS transformation is the most versatile image product to be segmented and classified. The mapping approach is based on information from both image texture and statistics, and has the advantage of reducing interpretation bias introduced by analyst during contextual editing. We also show that the hybrid mapping scheme that uses automated and visual image interpretation is particularly useful for mapping the ESI and LULC.
\end{abstract}

Keywords: Environmental sensitivity index; digital image processing; remote sensing.

\section{INTRODUCTION}

ESI maps are essential components of oil spill contingency planning that indicate substrates demanding specific clean-up actions and response options considering ecological, recreational and commercial concerns (Halls et al., 1997). There are, however, coastal segments with an acute lack of environmental information, not to mention updated cartographic databases. This is the case for most of the north and northeast Brazil, where portions of the coast virtually devoid of information are interspersed with regional administrative centers where environmental data are available. Contrasting with that, sensitivity index maps are now mandatory in Brazil for any company to explore, produce or transport oil and its products.

This is the typical scenario where remote sensing data can effectively aid the acquisition of updated and relevant environmental data over large stretches of the coast $(>100 \mathrm{~km})$ and the generation of sensitivity maps (Jensen, et al., 1990; Jensen et al., 1993; El-Raey et al., 1996; Abdel-Kader et al., 1998). Remote sensing images are also invaluable for the identification and mapping of submerged and intertidal habitats. The use of ESI maps can also be easily extended to include planning of environmental management of coastal areas by adding land use/land cover (LULC) themes.

The selection of appropriate remote sensing data and the applicable digital image processing techniques follows a compromise between costs and mapping capabilities, including coverage area, spectral and spatial resolution (Green, 2000). Computer-based supervised classification of multispectral imagery demands extensive field survey to reduce misclassification, yielding average accuracy figures around $70 \%$. On the other hand, visual interpretation from color composites of TM images has been considered as ground truth because it relies on context-dependent decisions carried out by the human brain (Green et al., 2000). However, the dependency on the visual interpretation skills and subjectivity of the analyst is generally considered a major drawback.

In this paper we present a mapping scheme that makes use of automated and visual Landsat ETM+ 
image interpretation to generate ESI and LULC maps. Initially, ETM images were radiometrically corrected to surface radiance and submitted to a restoration filter. Next, spectral transformation based on IHS and image filtering were performed. The IHS images were segmented and submitted to unsupervised classification to be evaluated for contextual editing. Visits to the field, assisted by global positioning system, were carried out to determine shoreline sensitivity, LULC classes, and compare classification results.

\section{MATERIALS AND METHODS}

We have investigated a $140 \mathrm{~km}$ long section of the northeast Brazilian coast (Fig. 1) located on the second largest oil bearing sedimentary basin in Brazil, called the Potiguar basin measuring $41000 \mathrm{~km}^{2}$ (Bertani et al., 1990). The coastline has a NW/SE orientation and is formed by a complex system dominated by medium to fine sand beaches, bounded by the Jaguaribe river to the northwest (Ceará state), and Mossoró river to the southeast (Rio Grande do Norte state). The area is characterized by a number of sensitive coastal habitats, including a wave-dominated delta in the mouth of Jaguaribe river. To the southeast a system of mobile low-tide sand terraces dominates the mouth of Mossoró river. The Icapui estuary is located in the central portion of the study area, which is fed by water seeps flowing from Tertiary sandstone (Barreiras Formation) outcropping $2 \mathrm{~km}$ inland. In front of this estuary there is also a well developed $32 \mathrm{~km}^{2}$ low-tide fine sand terrace located, with subtidal algal beds at the distal portion. This biological resource has been continuously explored by the local community that sells sun-dried seaweeds to the cosmetic industry. Important changes in LULC in the region, associated to the substitution of traditional salinas for the more lucrative shrimp farming, have

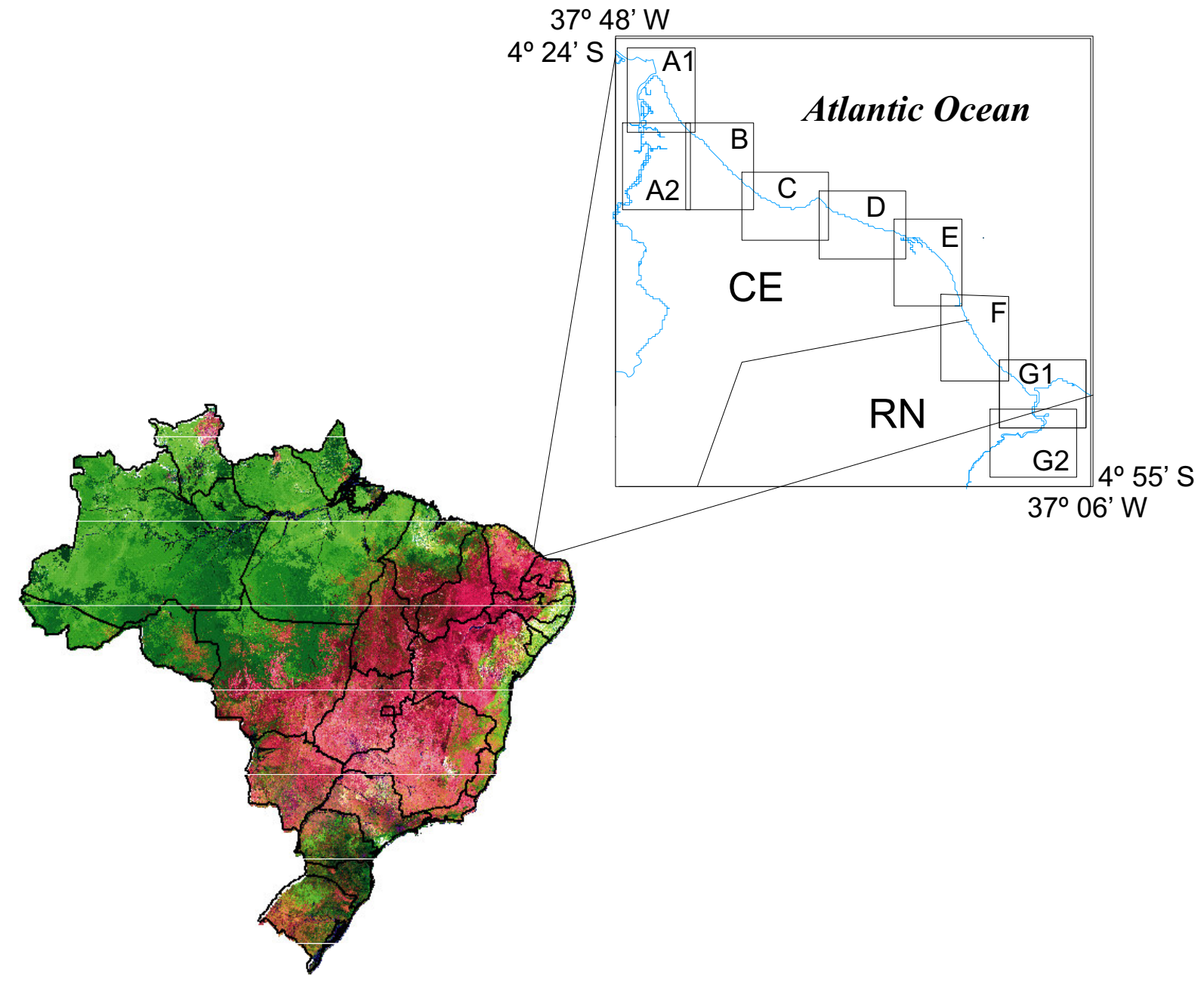

Figure 1 - The study area covers $140 \mathrm{~km}$ of coastline and is located in the Northeast Region of Brazil, including the Potiguar and Ceará sedimentary basins. The ESI maps are labeled from A to $\mathrm{G}$. 
recently raised concerns. This land-use change has been generally followed by acute land-cover changes with the conversion of mangrove areas to shrimp grow-out ponds.

\section{Field data collection}

We visited the study area in three different occasions to gather detailed information on land cover, wave and current exposure, and composition of the different substrates. A total of 27 beach sediment samples were collected to aid the determination of sediment texture necessary to assign beach sensitivity. A sensitivity index oriented data gathering protocol was devised to guarantee maximum efficiency during fieldwork, which included interviews with local fishermen, shrimp farm owners and villagers.

\section{Digital image processing}

Image processing scheme (Fig. 2) starts with Landsat ETM+ (216/063 acquired in 13/08/1999) multispectral bands (except the thermal infrared band 6) and the panchromatic (pan) band being corrected to surface reflectance using the 6S code (Second Simulation of the Satellite Signal in the Solar Spectrum, Vermote et al., 1997). Images were submitted to a restoration filter (Fonseca et al., 1993) that corrects for electronic noise and allows the resampling of multispectral bands to $15 \mathrm{~m}$, and the pan band to $5 \mathrm{~m}$ of pixel size. All routines used for digital image processing and geodatabase creation were carried out on the software SPRING (Câmara et al., 1996). After atmospheric correction and restoration, the panchromatic image was georeferenced using ground control points, and subsequently used for co-registration of multispectral bands.

The pre-processed images were used to generate standard and selective (eigenimages for the visible bands 1, 2 and 3) Principal Component (PC) images (Chavez et al., 1989; Manière et al., 1991), component fractions from Spectral Mixture Model (SMM) (Shimabukuro and Smith, 1991; Shimabukuro et al., 1998; Aguiar et al., 1999), Soil Adjusted Vegetation Images (SAVI) (Huete, 1988), and Intensity, Hue, Saturation (IHS) transform. The aim was to visually estimate their performance in terms of a consistent segmentation and classification of most coastal environments and LULC themes, particularly vegetation cover. A good classification has to contribute for contextual editing creating a sufficiently large number of regions, and a low level of misclassification.

IHS transformation (Carper et al., 1990; Harris et al., 1994) has been applied to the RGB (Red, Green and Blue) composite of ETM bands 1, 2, and 3, restored to $15 \mathrm{~m}$ pixel size. The pan image restored to $5 \mathrm{~m}$ pixel size replaced the intensity image produced by the spectral transformation of the RGB composite. Prior to the substitution the pan image was normalized to the reference intensity image created by IHS transformation (Gross and Schott, 1998). The process is completed when the intensity, hue and saturation images are transformed back to RGB space.

The processed images were segmented using a region growth algorithm (Bins et al., 1996) that establishes each region as a set of homogeneous pixels grouped according to their radiometric and spatial properties (Zucker, 1976). Algorithm functioning is briefly described as follows: first, let $D\left(R_{i}, R_{k}\right)=\left\|M_{i}-M_{k}\right\|$ be the Euclidean distance between the spectral mean values of the regions $R_{i}$ and $R_{k}$, and let $N(R)$ be the set of neighboring regions of $R$. Then, a list of regions $\left\{R_{p} i\right.$ $=1, \ldots, n\}$ is created ( $n$ is the number of pixels in the image). Segmentation starts with a seed pixel for each $R_{i}$ where mean value vector and neighboring regions are stored. The most similar neighboring region $R_{k} \in N\left(R_{i}\right)$ is chosen, so that if $D\left(R_{i}, R_{k}\right)<\mathrm{T}(\mathrm{t})$, then $R_{k}$ is the best neighbor of $R_{i}$ and both regions are merged. $T(t)$ is the similarity threshold value at instant $t$ and, initially, only very similar regions are merged so that $T(t)=a^{t} T(0)$, with $T(0)>0, t=0,1,2, \ldots$ and $a<1$.

Segmentation parameters were selected empirically, similarity threshold was set to 5 , which is the maximum Euclidean distance between the mean digital numbers of two regions that will determine their grouping. The area threshold has been set to 50 pixels for images with $15 \mathrm{~m}$ pixel size, and 150 pixels for images with $5 \mathrm{~m}$ pixel size (restored images).

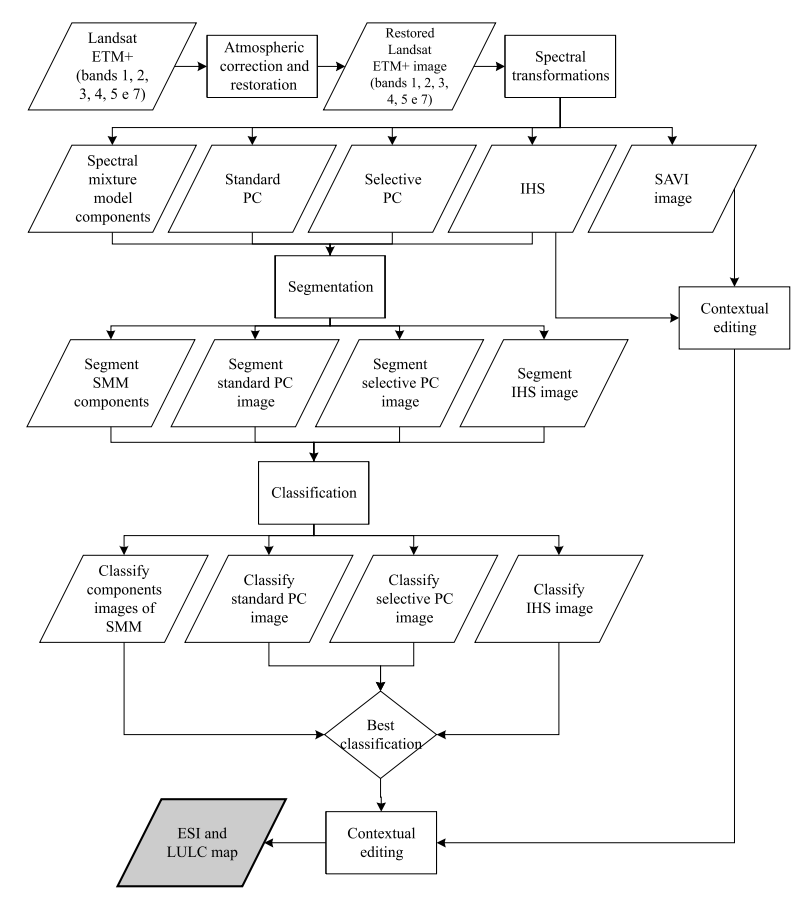

Figure 2-Image processing scheme showing the hybrid automated and visual image interpretation for ESI and LULC mapping. 
The unsupervised classification clustering algorithm ISOSEG (Bins et al., 1993) was applied to the segmented images and the per-region acceptance threshold has been set to $99 \%$. This threshold is defined as the maximum value of the Mahalanobis distance that regions can be apart to be considered as pertaining to the same class. The classification algorithm uses the covariance matrix and mean vector of the regions to estimate the centers of each class. This procedure generates a large number of classes, making it easier to map coastal environments and LULC units.

\section{ESI and LULC mapping}

Environmental sensitivity index (ESI) maps include information on shoreline classification, biological and human-use resources, allowing shoreline habitats to be ranked according to the biological sensitivity, natural persistence of oil and ease of clean-up. Information on biological resources includes oil-sensitive animals and non-shoreline habitats such as submerged aquatic vegetation and coral reefs. Specific areas that incorporate added sensitivity and value to humans such as high-use beaches, parks, marine sanctuaries and water intake are grouped into human-use resources (Michel et al., 1978; Gundlach e Hayes 1978; Michel, 1998). Ranking of coastal environments range from ESI 1 , low sensitivity coasts, to ESI 10 , high sensitivity coasts (Table 1) and expresses the relationships among physical processes, substrate type, and associated biota (Halls et al., 1997).

All maps were produced by matrix editing of unsupervised classification aided by visual interpretation of the transformed images. Editing regrouped classes into a LULC legend based on the phytoecology classes proposed by IBGE (1992), and complemented with information collected during visits to the field. At a later stage, all mapped LULC classes were transformed from raster into vector polygons. Biological and human-use resources necessary for the determination of ESI were edited as vectors onto LULC units, which helped to derive the occurrence of sensitive habitats and biological communities. The empirical accuracy of the segmentation/classification scheme has been assessed based on field verification of results for each class. Confusion and adequacy of class generalization to the research purposes were heuristically checked (see Shimabukuro et al, 1998 for a similar approach).

The logical structure of the geographic database was developed based on the object-oriented data model for geographic applications called OMT-G (Object Modeling Technique for Geographic Applications) (Borges et al., 2001), based on the classic OMT class diagram notation. The OMT-G allowed the representation of the geometry and topology of spatial data with diagrams representing object classes and their
Table 1 - ESI shoreline classification (Michel, 1998).

\begin{tabular}{cl}
\hline \hline ESI & \multicolumn{1}{c}{ Description } \\
\hline 1A & Exposed rocky shores \\
1B & Exposed, solid man-made structures \\
2A & Exposed wave-cut platforms in bedrock, mud, or clay \\
2B & Exposed scarps and steep slopes in clay \\
3A & Fine- to medium-grained sand beaches \\
3B & Scarps and steep slopes in sand \\
4 & Coarse-grained sand beaches \\
5 & Mixed sand and gravel beaches \\
6A & Gravel beaches \\
6B & Riprap \\
7 & Exposed tidal flats \\
8A & Sheltered rocky shores and sheltered scarps in bedrock, \\
8B & mud, or clay \\
8C & Sheltered, solid man-made structures \\
8D & Vegetated, steeply-sloping bluffs \\
9A & Sheltered tidal flats \\
9B & Vegetated low banks \\
10A & Salt-and brackish-water marshes \\
10B & Freshwater marshes \\
10C & Swamps \\
10D & Scrub-shrub wetlands \\
\hline \hline
\end{tabular}

relationships, transformation operations between classes, and various visual aspects necessary to represent each object class.

\section{RESULTS}

\section{Visual interpretation of restored images and spectral transformations}

The restoration filter applied to the ETM images sharpened most linear features such as roads (both paved and unpaved) city blocks, rivers and small channels, and shoreline. As a result, greater separability was achieved for low contrast landscape features such as small coastal villages, salt and shrimp ponds. It also helped in the definition of some coastal habitats, namely mangroves

All classification products, contextual editing, and definition of map themes were checked in the field, and the resulting maps can be regarded as an adequate approximation to ground truth. The resulting LULC legend for the study area is as follows: coastal dune, coastal sand deposit vegetation (hereafter refereed to as restinga), bare soil, forested steppe savannah, scrub steppe savannah, steppe savannah woodland, steppe savannah complex, grassland steppe savannah complex, mangrove, cashew crop, palm (coconut and/ or carnaúba palm), salt pond, urban area, and village.

Classification of segmented IHS images produced optimum spectral separation and class partitioning with a large number of classes and negligible misclassification (Fig. 3). Classification was consistent across different environmental units within the study area without spectral artifacts, and improved overall efficiency 
of contextual editing and ESI/LULC mapping (Fig. 4). The combined use of a restoration filter and IHS transformation allowed a clear delimitation of most coastal environments and linear features such as nonpaved roads that are used as accesses to different portions of the shoreline.

\section{ESI and LULC mapping}

Classification of IHS merged images allowed the direct ESI mapping of mangrove forests (10D), exposed and protected intertidal and subtidal habitats (7 and 9A/ 9B). Classes pertaining to other ESI habitats were mapped from contextual editing of classification aided by visual inspection of IHS composites. Data necessary for ESI maps, such as location and area extension of coastal environments, accesses to shoreline, and substrate trafegability, have been retrieved from GIS operations performed on the geodatabase. A total of nine 1:50 000 maps representing coastal sensitivity to oil spill (Fig. 5) were produced, and included river drainage, sensitivity index, accesses, biological and human-use resources, and LULC. Sensitivities assigned to the shoreline and intertidal/subtidal environments were represented by lines and polygons linked to tables with detailed biological information.

Fine-grained sand beaches (ESI 3A/3B) predominate in all coastal segments, extending along

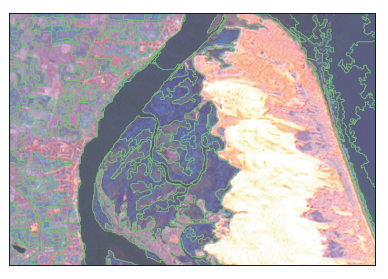

a

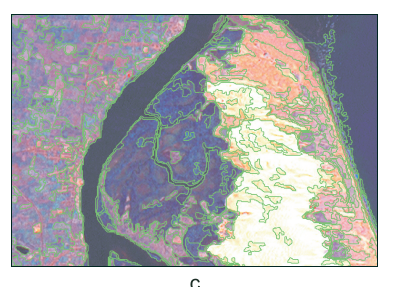

c

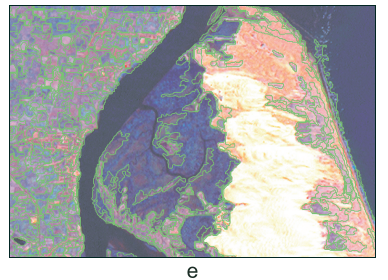

Figure 3 - Example of the segmentation by region growth algorithm for different image processing products (background is an IHS composite): (a) PC1 of the standard PC; (b) PC1 of bands ETM1, 2, and 3, PC1 of bands ETM5, 7 and band ETM4; (c) shadow fraction image; (d) vegetation fraction image; (e) soil fraction image; and ( $f$ ) IHS image. Segmented area is part of the map A1 seen in Figue 1 and is $9 \mathrm{~km}$ across.
$112.5 \mathrm{~km}$ of coastline, while exposed tidal flats (ESI 7) represents the greatest surface-related index with 37.7 $\mathrm{km}^{2}$. A sequence of co-occurring substrates composed of impermeable exposed rocky cliffs (mostly associated to the Barreiras Formation, ESI 1A), sand beaches (ESI $3 \mathrm{~A} / 3 \mathrm{~B})$ or wave-cut rock platforms $(2 \mathrm{~A})$ has been observed in the beaches of Canoa Quebrada, Retirinho, Ponta Grossa, Barreiras and Barrinha.

Fine- to medium-grained sand deposits extends along $13 \mathrm{~km}$ of the western banks of the Jaguaribe river and were classified as ESI 3D. This index does not exist in the original scale of the ESI, and was taken from the Reach Sensitivity Index (RPI, 2003). Some gravel deposits (ESI 6A) have also been found along $1.5 \mathrm{~km}$ of this side of the river. These sand banks and gravel deposits occur along the base of the tectonically generated sheltered rocky shores (ESI 8A).

Exposed tidal flats (ESI 7) occur in the Jaguaribe river, Mossoró river and Icapuí estuaries and near Upanema beach. Sheltered tidal muddy flats (ESI 9A) occurs in the Jaguaribe and Mossoró river estuaries (Pontal de Maceió and Barra de Upanema, respectivelly), and are generally associated to mangroves. Vegetated low banks (ESI 9A, 9B) also occur in the Jaguaribe river eastern banks, close to the estuary, which are highly sensitive to oil. Mangroves (ESI 10D) occur in higher densities in the Jaguaribe river eastern banks, in the Mossoró river and in the Icapuí estuary.

\section{DISCUSSION}

The study area is characterized by diverse coastal environments with highly fragmented land use and vegetation cover types, the latter resulting from over a century of human-use impacts. Thematic mapping from
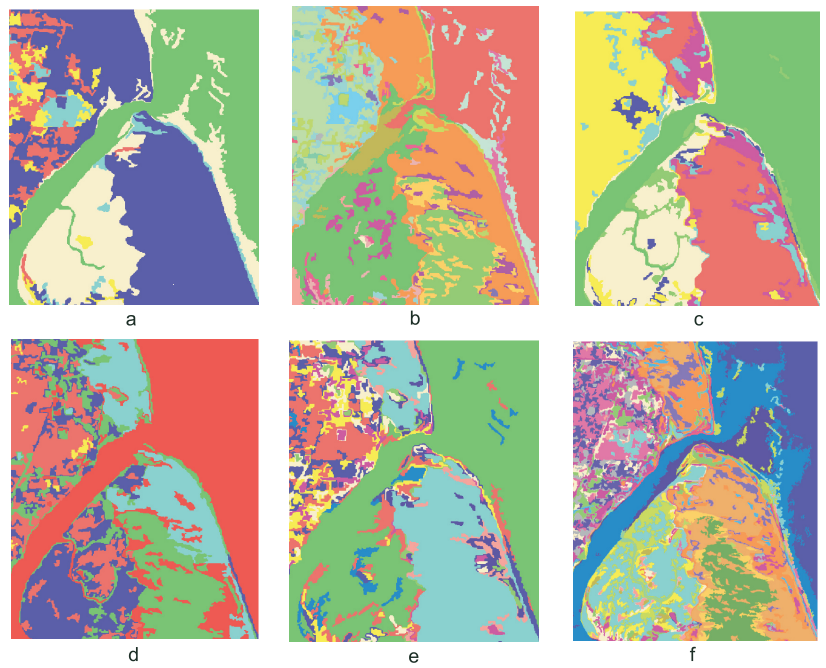

Figure 4 - Unsupervised digital classification of the segmented images. Legend is the same as in Figure 3. 


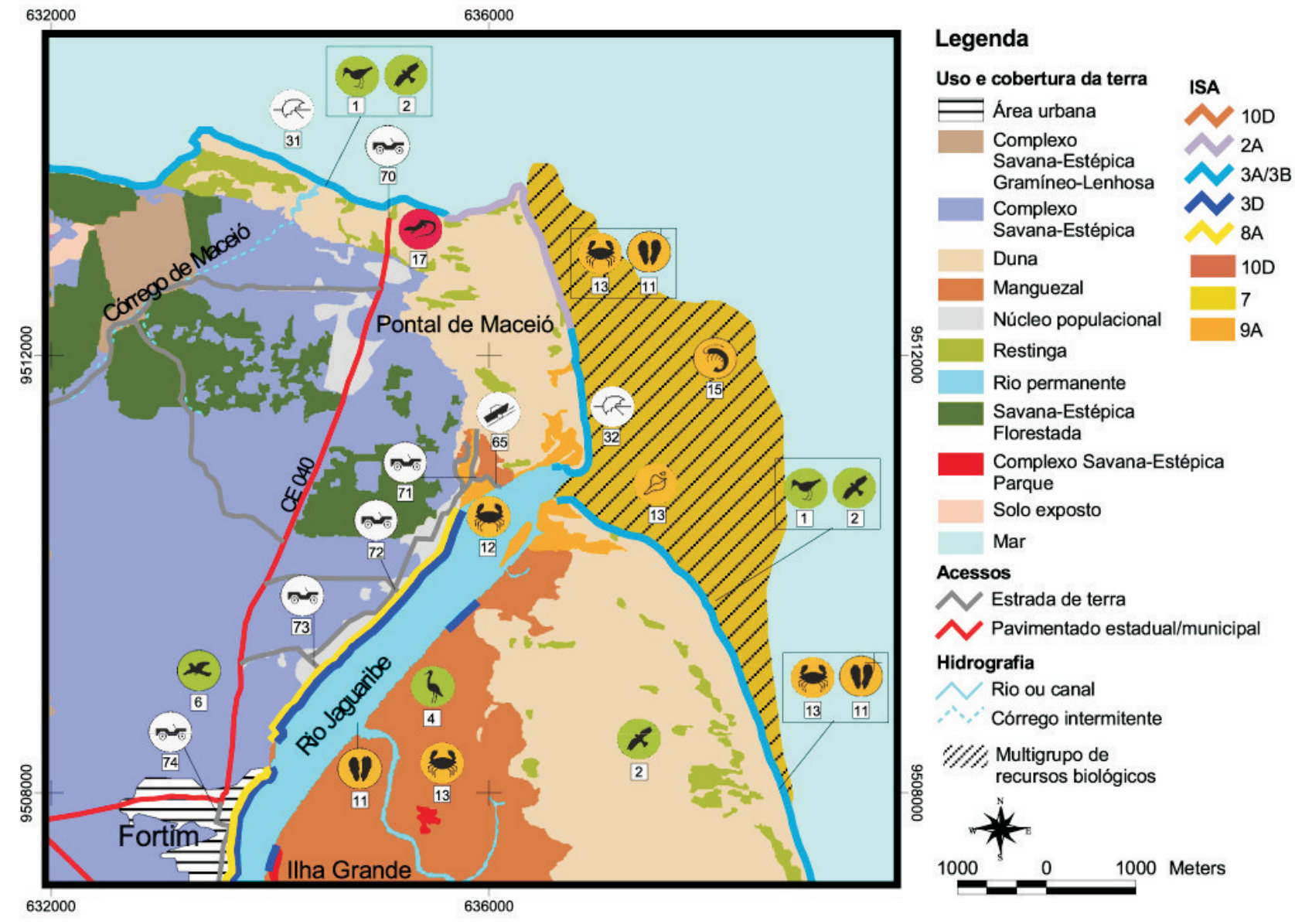

Figure 5 - Detail of the ESI map from the Jaguaribe River, in Ceará state. Shoreline and habitats are colored following the sensitivity index color code (Halls et al, 1997). Symbols indicate the location of biological and human-use resources.

remote sensing data relies on image classification, achieved by either visual or computer-aided analysis (Foody, 2002). We have attempted a hybrid approach for ESI and LULC mapping, based on image segmentation and unsupervised classification supported by visual image interpretation and ground truth. This has been devised to reduce analyst bias during visual interpretation caused by incomplete knowledge of the environments that are being mapped. It also has the potential to reduce the need for expert knowledge upon local environments found along the highly diverse Brazilian coastline. The option for the region growth segmentation was based on the advantage of connecting pixels into a physical region with similar properties on the earth, which are clustered in a spatialspectral fashion. Since all classification products were checked in the field and classification editing was carried out based on field information, the resulting maps can be regarded as a close representation of ground truth.

Spectral transformations were selected according to their capabilities to improve target definition, and discrimination of coastal environments after being submitted to segmentation and classification algorithms. For a proper contextual editing classification has to consistently discriminate major environments and generate at least twice as many classes as required so that analyst can merge or delete classes with reference to field data (cf. Green et al., 2000). Our results show that total number of classes is not a sufficient condition for a good classification performance, but adequate definition of linear features and other high frequency information such as LULC boundaries within the scene are also important. Definition of themes followed recommendations from IBGE (1992) but the original vegetation cover has been largely altered imposing limitations to the strict use of classification protocols.

Merging of the restored ETM panchromatic image with the restored multispectral bands in the IHS system improved visual interpretability due to edge enhancement and high contrast of different scene targets. This allowed the detection and mapping of paved and unpaved roads, coastline, fluvial and tidal channels, and small coastal villages. Contrast between different LULC units has also been increased, maximizing the number of classes 
generated by the segmentation/classification procedure. SAVI images failed to produce a good classification of open vegetation, but it was used for contextual editing of cashew crop and pioneer vegetation such as those found on coastal sand deposits. The identification of linear features and boundaries between different environments is of paramount importance for ESI mapping because it allows the determination of location and spatial extent of biological and human-use resources. Accesses to river banks, beaches, and limits to intertidal habitats became easily discernable, helping to correctly assign sensitivity indexes.

Standard PC analysis of all ETM bands (except for band 6) was run prior to the selective PC to check for overall interband correlation, and showed that the first principal component concentrated only $87.44 \%$ of total variance. This higher dimensionality has been also detected in the correlation matrix (Table 2) indicating high correlation among bands from the visible (bands ETM1, 2 and 3), and the infrared spectra (bands ETM4, 5 and 7 ). Band loadings for all eigenvectors show major spectral contrasts in bands ETM1, 4, and 5 (Fig. 6), possibly associated to water and vegetation reflectances. In fact, the first eigenvector has all positive band components within a very narrow loading interval, as seen in Figure 3. Results from the selective PC procedure increased variance concentration on the first component to $93.09 \%$ and $99.25 \%$ for the visible and infrared ETM bands, respectively.

Table 2 - Correlation matrix indicating high correlation among bands from the visible (bands ETM1, 2 and 3), and the infrared spectra (bands ETM4, 5 and 7). Note that band ETM3 is highly correlated with all bands.

\begin{tabular}{ccccccc}
\hline \hline Bands & $\mathbf{1}$ & $\mathbf{2}$ & $\mathbf{3}$ & $\mathbf{4}$ & $\mathbf{5}$ & $\mathbf{7}$ \\
\hline 1 & 1.000 & - & - & - & - & - \\
2 & 0.966 & 1.000 & - & - & - & - \\
3 & 0.815 & 0.926 & 1.000 & - & - & - \\
4 & 0.653 & 0.766 & 0.896 & 1.000 & - & - \\
5 & 0.623 & 0.736 & 0.897 & 0.964 & 1.000 & - \\
7 & 0.655 & 0.776 & 0.927 & 0.936 & 0.984 & 1.000 \\
\hline \hline
\end{tabular}

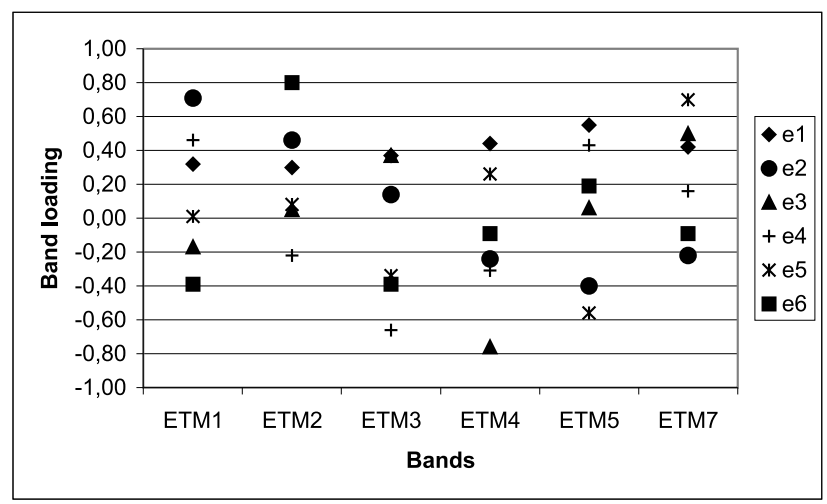

Figure 6 - Eigenvectors (e1 to e6) for the PC of six ETM+ bands. Note slightly larger spectral contrasts in bands ETM1, 4, and 5, possibly associated to vegetation and water reflectances.

\section{CONCLUSIONS}

Image restoration and the consequent reduction in pixel size improved the definition of linear features without introducing the sawtooth effect or radiometric artifacts. Merging of the restored ETM panchromatic image with the restored multispectral bands via IHS maximized the number of classes generated by the segmentation/classification procedure, making it easier to map these classes. It also improved the contrast between different LULC units and the visual identification of paved and unpaved roads, fluvial and tide channels, and small villages.

SAVI images were of limited use but helped the contextual editing of cashew crop and pioneer vegetation. Classification of IHS merged images also allowed the direct mapping of the ESI for mangrove forests (10D), exposed and protected and highly sensitive intertidal and subtidal habitats ( 7 and 9A/9B). The use of automated and visual image interpretation proved to be particularly useful for mapping the ESI and LULC.

\section{ACKNOWLEDGEMENTS}

The authors are immensely grateful to Dr. Cláudia Z. F. Braga for her generosity and wholehearted support to the project. Financial support was provided by Oceansat under the scientific cooperation agreement with INPE no. 01.01.035.0/2001, and postgraduate grant to M.C. provided by CAPES/Brazil.

\section{REFERENCES}

Abdel-Kader, A.F.; Nasr, S.M.; El-Gamily, H.I. \& El-Raey, M. 1998. Environmental sensitivity analysis of potencial oil spill for Ras-Mohammed Coastal Zone, Egypt. Journal of Coastal Research, 14:502-510.

Aguiar, A.P.D.; Shimabukuro, Y.E. \& Mascarenhas, N.D.A. 1999. Use of synthetic bands derived from mixing models in the multispectral classification of remote sensing images. International Journal of Remote Sensing, 20: 647-657.

Bertani, R.T.; Costa, I.G. \& Matos, R.M.D. 1990. Evolução tectono-sedimentar, estilo estrutural e habitat do petróleo na Bacia Potiguar. In: Gabaglia, G.P.R. e Milani, E.J. (Eds.), Origem e evolução de bacias sedimentares, Petrobrás, 291-310pp.

Bins, L.S.; Erthal, G.J. \& Fonseca, L.M.G. 1993. Um Método de Classificação Não Supervisionada por Regiões. In: Simpósio Brasileiro de Computação Gráfica e Processamento de Imagem, 6, Anais. Recife: SBPC, 65-68pp. 
Bins, L.S.; Fonseca, L.M.G.; Erthal, G.J. \& li, F.M. 1996. Satellite imagery segmentation: a region growing approach. In: Simpósio Brasileiro de Sensoriamento Remoto, 8, Anais. Salvador: INPE, 221-223pp.

Borges, K.A. de V. 1997. Modelagem de dados geográficos: Uma extensão do modelo OMT para aplicações geográficas. Dissertação de Mestrado em Administração Pública, Escola de Governo, Fundação João Pinheiro, Belo Horizonte, 128p.

Câmara, G.; Souza, R.C.M.; Freitas, U.M. \& Garrido, J. (1996), SPRING: Integrating remote sensing and GIS by object-oriented data modelling. Computers \& Graphics, 20: 395-403.

Carper, W.J. \& Lillesand, T.M. \& Kiefer, R. 1990. The use of intensity-hue-saturation transformations for merging SPOT panchromatic and multispectral image data. Photogrammetric Engineering and Remote Sensing, 56:459-467.

Chavez, P.S \& Kwarteng, A.Y. 1989. Extrating spectral contrast in Landsat Thematic Mapper image data using selective principal component analysis. Photogrammetric Engineering and Remote Sensing, 55:339-348.

El-Raey, M.; Abdel-Kader, A.F.; Nasr, S.M. \& Gamily, H.I 1996. Remote sensing and GIS for an oil spill contingency plan, Ras-Mohammed, Egypt. International Journal of Remote Sensing, 17:20132026.

Fonseca, L.M.G.; Prasad, G.S.S.D. \& Mascarenhas, N.D.A. 1993. Combined interpolation - restoration of Landsat images through FIR filter techiniques. International Journal of Remote Sensing, 14:25472561.

Foody, G.M. 2002. Status of land cover classification accuracy assessment. Remote Sensing of Environment, 80:185-201.

Green E.P.; Clark C.D. \& Edwards A.J. 2000. Image classification and habitat mapping. In: Edwards A.J. (Ed.) Remote Sensing Handbook for Tropical Coastal Management, Costal Management Sourcebooks 3, France: UNESCO Publishing, 141154pp.

Green, E. 2000. Satellite and airborne sensors useful in coastal applications. In: Edwards A.J. (Ed.) Remote Sensing Handbook for Tropical Coastal Management, Costal Management Sourcebooks 3, France: UNESCO Publishing, 41-56pp.

Gross, H.N. \& Schott, J.R. 1998. Application of spectral mixture analysis and image fusion techniques for image sharpening. Remote Sensing of Environment, 63:85-94.

Gundlach, E \& Hayes, M. 1978. Vulnerability of coastal environments to oil spill impacts. Marine Technology Society, 12:18-27.
Halls, J.; Michel, J.; Zengel, S. \& Petersen, J. 1997. Environmental sensitivity index guidelines, version 2.0. NOAA Technical Memorandum NOS ORCA 115. Seattle: Harzadous Materials Response and Assessment Division, National Oceanic and Atmospheric Administration, 79p.

Harris, J.R.; Bowie, C.; Rencz, A.N. \& Graham, D. 1994. Computer-enhancement techniques for the integration of remotely sensed, geophysical, and thematic data for the geosciences. Canadian Journal of Remote Sensing, 20:210-221.

Huete, A.R. 1988. A soil-adjusted vegetation index (SAVI). Remote Sensing of Environment, 25:295309.

Instituto Brasileiro de Geografia e Estatística (IBGE) 1992. Manual técnico da vegetação brasileira. Série Manuais Técnicos em Geociências, 01, Rio de Janeiro: IBGE, 92p.

Jensen, J.R.; Ramsey, E.W.; Holmes, J.M.; Michel, J.E.; Savitsky, B. \& Davis, B.A. 1990. Environmental sensitivity index (ESI) mapping for oil spills using remote sensing and geographic information system technology. International Journal of Geographical Information Systems, 4:181-201.

Jensen, J.R.; Narumalani, S.; Weatherbee, O.; Murday, M.; Sexton, W.J. \& Green, C.J. (1993), Coastal environmental sensitivity mapping for oil spills in the United Arab Emirates using remote sensing and GIS technology. Geocarto International, 2:5-13.

Manière, R.; Khiyar, H. \& Courboulès, J. 1991. Comparaison de différentes méthodes de traitement par analyses en composantes principales des données Thematic Mapper de LANDSAT-5 appliquées à l'inventaire forêts méditerrannéennes du sud de la France. International Journal of Remote Sensing, 12:1887-1903.

Michel, J. 1998. Environmental sensitivity mapping: a key tool for oil spill contingency planning and response. Exclusive Economic Zone Technology, 1:193-200.

Michel, J.; Hayes, M.O. \& Brown, P.J. 1978. Application of an oil spill vulnerability index to the shoreline of Lower Cook Inlet, Alaska. Environmental Geology, 2:107-117.

Shimabukuro, Y.E.; Batista, G.T.; Mello, MK.; Moreira, J.C. \& Duarte, V. 1998. Using shade fraction image segmentation to evaluate deforestation in Landsat Thematic Mapper images of the Amazon region. International Journal of Remote Sensing, 19:535541.

Shimabukuro, Y.E. \& Smith, J.A. 1991. The leastsquares mixing model to generate fraction images from remote sensing multispectral data. IEEE Transactions in Geosciences and Remote Sensing, 29:16-20. 
Braz. J. Aquat. Sci. Technol., 2008, 12(2):1-9.

Vermote, E.F.; Tanre, D.; Deuze, J.L.; Herman, M. \& Morcrette, J.J. 1997. Second simulation of the satellite signal in the solar spectrum, $6 \mathrm{~S}$ : An overview. IEEE Transactions in Geosciences and Remote Sensing, 35:675-686.
Zucker, S.W. 1976. Region growing: childhood and adolescence. Computer Graphics and Image Processing, 5:282-399.

Received: September 10, 2008 Accepted: December 19, 2008 